\title{
Etodolac Softgels: Feasibility Assessment and Considerations for Lipid-Based Formulations of a highly hydrophobic drug Ahmed N. Allam ${ }^{1,3}{ }^{*}$, Ibrahim A. Komeil ${ }^{2,4}$ Ossama Y. Abdallah ${ }^{1}$ \\ ${ }^{1}$ Department of Pharmaceutics, Faculty of Pharmacy, Alexandria University, Egypt ${ }^{2}$ R\&D pharmacist at Medizen Pharmaceutical Industries, Alexandria, Egypt \\ ${ }^{3}$ Department of Pharmacy Practice and Dosage Forms, Oman Pharmacy Institute, Sultanate of Oman \\ ${ }^{4}$ Department of Pharmaceutics, Faculty of Pharmacy, Pharos University, Alexandria, Egypt
}

*Corresponding Author E-mail: ph.a.allam@gmail.com

\begin{abstract}
Oral lipid-based formulations provide a significant opportunity to address the poor and variable gastrointestinal absorption associated with poorly water soluble drugs. It is useful to discuss how a formulation can strategize various options creatively to overcome some of the challenges posed by the softgel dosage form development of a highly hydrophobic drug with large dose. Etodolac (ETO) was formulated in different lipid vehicle according to Lipid Formulation Classification System (LFCS) to optimize the appropriate fill composition and was subjected to different tests for characterization. Water migration studies, rupture test and mechanical properties of softgels were also performed to investigate the effect of the formulation materials on the integrity, physical stability of the prepared capsules and on the dissolution characteristics of drug. Selected formulations were assessed for in vitro dissolution profile and rupture test for softgel before and after accelerated and shelf stability for 3 months. Results revealed a correlation between the composition of the softgel core fill liquid and drug dissolution parameters. Application of hydrophilic surfactants showed a remarkable enhancement in the dissolution rate of drug. The extent of migration of a solute between a fill and a shell depends on the hydrophilicity of the solute, composition of the shell formulation. Antioxidants should be added to formulations containing hydrophilic surfactants which composed of polyoxyethylene moiety. Nominated formula containing polyethylene glycol/poloxamar 407 showed a good and stable dissolution results after accelerated and shelf stability in addition to better mechanical results.
\end{abstract}

Key words: Dissolution; Etodolac; Lipid based formulations; Stability; Water migration

\section{INTRODUCTION}

Lipids are supposed to offer many prospective options for improving the absorption of poorly soluble drugs via decreasing the intrinsic boundaries of slow dissolution and by assisting formation of colloidal particles inside the intestine that are able to preserve lipophilic drugs in solution (Hauss 2007). Increasing the oral bioavailability of highly hydrophobic drug candidates through utilization of natural and/or synthetic lipids has been given a growing interest in recent years (Hauss 2007;
Gullapalli 2010). Lipid-based formulations (LBFs) provide a significant opportunity to manage irregular absorption associated with poorly water soluble candidates through processes that employ physicochemical, and physiologic, mechanisms controlling drug absorption (Pouton 2000; Patel et al., 2011). They have proven to improve drug absorption through inhibition of P-glycoprotein-mediated efflux, enhanced lymphatic drug transport and concomitant reduction of hepatic first pass metabolism, or through prolongation of gastrointestinal transit time, thereby allowing 
greater time for drug dissolution and absorption to occur(Hauss 2007). While fullysolubilized lipid-based formulations generally offer optimal absorption, drugs that cannot be completely solubilized in the lipid excipient matrix may be formulated as partiallysolubilized lipid suspensions. Excipients or excipient combinations should be optimized to conserve good physical stability of the dispersed drug in the lipid (Soumya et al., 2012).

Efforts to develop tablet formulations containing sufficient quantities of lipid and surfactant excipients to solubilize a poorly water-soluble drug have met with limited success due to the tendency for these excipients to compromise the physical integrity and mechanical strength of conventional compressed tablets. Nevertheless, most LBFs are compatible with either hard gelatin capsule or soft gelatin capsule (softgel) shells, which allow the development of commercially viable oral dosage forms (Gullapalli 2010).

Oral delivery of hydrophobic drug candidates via softgel technology is of increasing significance(Bottom et al., 1997; Hong et al., 1998; Yang et al., 2006). Softgels present numerous advantage such as delivering of liquid solubilized matrix, enhancing bioavailability of poorly soluble compounds, keeping the encapsulated compound in protection against oxidation, and minimizing possible production of dust during manufacturing and in so doing the safety of personnel convenience would be increased (Gullapalli 2010; Benza et al., 2011). Several consumer acceptance expressing their preference for softgels have been established, in terms of ease of swallowing, taste and convenience (Jones 2000).

Physical migration between shell and fill component besides shell and external surroundings in addition to incidence of physical and chemical interactions inside and among shell and fill components represent major challenges in the development of the softgels to build up a stable softgel product with a preferred in vitro and in vivo performance (Gullapalli 2010; Benza and Munyendo 2011).

Etodolac (ETO) is a non-steroidal antiinflammatory drug that safely treat inflammatory disorders including rheumatoid arthritis, osteoarthritis and acute pain at 400 $\mathrm{mg}$ in divided oral dose ; up to $1200 \mathrm{mg}$ (Ibrahim et al., 2010). Clinical studies revealed that ETO could induced anti carcinogenic effects on various human cancer cells (Tsuneoka et al., 2005; Okamoto et al., 2008). It is practically water insoluble drug and is considered to be a class II drug; that is characterized by low solubility and high permeability (Yazdanian et al., 2004; Karataş et al., 2005) .

In the present work, ETO was formulated in different lipid vehicle according to Lipid based Formulation Classification Systems (LFCS) which were subjected to different tests to examine the effect of the formulation on the integrity, physical and chemical stability of the prepared capsules and on the dissolution characteristics of drug to select appropriate fill composition. Selected formulations were evaluated for in vitro dissolution profile and rupture test for softgel before and after accelerated and shelf stability for 3 months.

\section{MATERIALS AND METHODS Materials}

Etodolac (ETO) was kindly supplied by Kreative organics, India; Polyethylene glycol 400 (PEG 400), Hydrogenated vegetable oil Type I (HVO-I) and Type II (HVO-II) by Parchem, USA; Bees wax by Kahlwax, Germany; Propylene glycol (PG) by Arrowchem, China; Soya bean oil (SBO), Soya lecithin oil (SLO) by Adm, USA, 
Zagazig J. Pharm. Sci. Jun, 2017

Vol. 26, Issue 1, pp, 1-12

Poloxamer 407 (PLX 407) by Croda, USA; Cremophor EL and Cremophor RH by Basf, USA and high-performance liquid chromatography (HPLC) grade Acetonitrile by Merk Co, Hohenbrunn, Germany. All reagents and chemicals were of analytical grade.

\section{Determination of Required HLB value for oily mixtures}

Required HLB of the dispersion phase was studied experimentally to determine the most appropriate HLB value of hydrophilic surfactant mixture to avoid separation of LBFs of ETO(Griffin 1949). Calculated weight of emulsifier blends (Span 80/Tween 80) was added to melted oil at $50^{\circ} \mathrm{C}-60^{\circ} \mathrm{C}$ in a glass bottle and the mixture was agitated well. At the same temperature, water was added at one time and the glass bottle was tightly closed and shaken, the emulsion was stored overnight in a controlled temperature water bath at $37^{\circ} \mathrm{C}$ $40^{\circ} \mathrm{C}$.
1SSN 2356_9786

ISSN (on-line) 2356_9786

\section{Preparation of LBFs of ETO}

Lipid fill formulations were prepared according LFCS suggested by Pouton (Pouton 2000; Pouton 2006 ) and Porter et al(Porter et al., 2008). Compositions of softgel fill formulations were shown in Table 1.

Dispersion method (LL Schramm 2005) was used to prepare solid-in-liquid suspension for LBFs to be encapsulated into softgels. Briefly, excipients were melted at $70^{\circ} \mathrm{C}$ in a water bath (Bunsen, India) and ETO was dispersed mechanically by a magnetic stirrer with application of a homogenizer (IKA T25, Germany) till obtaining a homogenize dispersion in the molten mass. For formulations containing PLX 407 and cosolvents, PLX 407 was molten with its cosolvent at $52{ }^{\circ} \mathrm{C}-57{ }^{\circ} \mathrm{C}$ then added to the prepared oily molten mass with continuous stirring before ETO dispersion in the prepared liquid vehicle.

Table 1: Composition of Lipid based formulations (LBFs) of Etodolac

\begin{tabular}{|c|c|c|c|c|c|c|c|c|c|}
\hline & \multicolumn{9}{|c|}{ LBFs according lipid formulation classification system (LFCS) } \\
\hline & I & \multicolumn{2}{|c|}{ II } & \multicolumn{3}{|c|}{ III $_{\mathbf{a}}$} & \multicolumn{2}{|c|}{ III $_{\mathbf{b}}$} & IV \\
\hline & Oil & \multicolumn{2}{|c|}{$\begin{array}{c}\text { Oil and water } \\
\text { insoluble surfactant }\end{array}$} & \multicolumn{3}{|c|}{ Oil and water soluble surfactant } & \multicolumn{2}{|c|}{$\begin{array}{c}\text { Oil, water soluble } \\
\text { SAA with co-solvents }\end{array}$} & $\begin{array}{c}\text { Water soluble } \\
\text { SAA }\end{array}$ \\
\hline & $\mathbf{F}_{1}$ & $\mathbf{F}_{2}$ & $\mathbf{F}_{3}$ & $\mathbf{F}_{4}$ & $\mathbf{F}_{5}$ & $\mathbf{F}_{8}$ & $\mathbf{F}_{6}$ & $\mathbf{F}_{7}$ & $\mathbf{F}_{9}$ \\
\hline ETO & 300 & 300 & 300 & 300 & 300 & 300 & 300 & 300 & 300 \\
\hline SLO & $\ldots$. & 60 & $\ldots \ldots$ & $\ldots \ldots$ & $\ldots \ldots$ & $\ldots \ldots$ & $\ldots \ldots$ & $\ldots \ldots$ & $\ldots \ldots$ \\
\hline Span 85 & ...... & $\ldots$. & 60 & $\ldots \ldots$ & $\ldots$ & $\ldots \ldots$ & ........ & $\ldots \ldots$ & $\ldots \ldots$ \\
\hline CRM El & $\ldots \ldots$ & ..... & $\ldots \ldots$ & $\ldots \ldots$ & $\ldots \ldots$ & 106.68 & $\ldots \ldots$ & $\ldots \ldots$ & $\ldots \ldots$ \\
\hline CRM RH 40 & $\ldots \ldots \ldots$ & ..... & $\ldots \ldots$ & 120 & ....... & $\ldots \ldots$ & $\ldots \ldots$ & $\ldots \ldots$ & 600 \\
\hline PEG 400 & $\ldots \ldots$ & $\ldots .$. & $\ldots \ldots$ & $\ldots \ldots$ & ....... & $\ldots \ldots$ & $\ldots \ldots$ & 360 & $\ldots \ldots$ \\
\hline PG & $\ldots \ldots \ldots$ & $\ldots \ldots$ & $\ldots \ldots$ & $\ldots \ldots$ & ....... & $\ldots \ldots$ & 360 & $\ldots \ldots$ & $\ldots \ldots$ \\
\hline PLX 407 & $\ldots \ldots$ & $\ldots \ldots$ & $\ldots \ldots$ & $\ldots \ldots$ & 120 & 13.32 & 120 & 120 & $\ldots \ldots$ \\
\hline Bees wax & 6 & 5.1 & 5.4 & 4.8 & 4.8 & 4.8 & 1.2 & 1.2 & $\ldots \ldots$ \\
\hline HVO-I & 7.99 & 6.8 & 7.18 & 6.4 & 6.4 & 6.4 & 1.6 & 1.6 & $\ldots \ldots$ \\
\hline HVO-II & 33.99 & 28.9 & 30.56 & 27.2 & 27.2 & 27.2 & 6.8 & 6.8 & $\ldots \ldots$ \\
\hline SBO & 552 & 469.2 & 496.8 & 441.6 & 441.6 & 441.6 & 110.4 & 110.4 & $\ldots \ldots$ \\
\hline
\end{tabular}

Note: Weights were expressed in mg. Ratio between ETO and oily mixture was 1:2

ETO, Etodolac; SLO, Soya lecithin oil; CRM El, Cremophor EL; CRM RH, Cremophor RH; PEG, polyethylene glycol; PG, propylene glycol; PLX, Poloxamer; HVO, Hydrogenated vegetable oil; SBO, Soya bean oil.

\section{Characterization of ETO fills formulations.} Drug Content

For each formula, one capsule was placed with $20 \mathrm{ml}$ of distilled water in a sonicator (Branson, Mexico) for 15 minutes at room temperature, and then diluted to $100 \mathrm{ml}$ with ethanol $95 \%$ in a tightly capped volumetric flask (Aboul-Einien, 2009). Samples were filtered and assayed for drug content spectrophotometrically at $278 \mathrm{~nm}$ using ethanol $95 \%$ as a blank. Results were average of three. 


\section{In-vitro dissolution study}

The dissolution studies were carried out at $37^{\circ} \mathrm{C} \pm 0.5^{\circ} \mathrm{C}$ for 60 minutes at stirring rate of 100rpm using USP apparatus I (Hanson, USA) in $1000 \mathrm{~mL}$ phosphate buffer $\mathrm{pH} 6.8 \pm 0.1$. Fill formulations were manually filled in hard gelatin capsule (size 0) equivalent to $300 \mathrm{mg}$ ETO and was added to the stirred dissolution medium at zero time. $10 \mathrm{ml}$ samples were withdrawn at different time intervals and filtered through $0.45 \mathrm{um}$ pore filter, $5 \mathrm{ml}$ of filtrate was diluted with 50 $\mathrm{ml}$ of phosphate buffer solution $\mathrm{pH} 6.8$; samples were measured spectrophotometrically at $278 \mathrm{~nm}$ using suitable blank.

\section{Characterization of ETO Softgels Water migration study}

With the purpose of studying the effect of core fill composition on the water sorption behavior of the softgels, water migration studies were investigated (AboulEinien 2009); three air filled softgels were injected manually by syringe with the fill formulations of ETO. Injected air filled capsules were weighed and placed in a controlled temperature room $\left(21^{\circ} \mathrm{C}-24^{\circ} \mathrm{C}\right)$ at relative humidity (20-30\%) to be permitted to come to moisture equilibrium under these conditions(Gullapalli 2010). The capsules were weighed every day for 7 days until constant weight indicating that equilibrated moisture absorption had been achieved. After equilibrium, the moisture content of the fill in a softgels was measured using a karl-Fisher apparatus (Metrohm, Switzerland), where the softgel was cut open at the seam with a knife and the fill was collected using a syringe, the fills were transferred into the titration vessel containing dried methanol and titrated with pyridine after stirring for 2 min (Aboul-Einien 2009; Gullapalli 2010).

Moisture content of the shell was calculated using loss on drying method

\section{ISSN (on-line) 2356_9786}

(LOD) in which softgels was opened at their seam through a knife and fill contents were wiped out. The shell was given a fast rinse with isopropyl alcohol and cleaned from any residual fill contents using a paper towel before beginning of measurements. The weight of the softgel was recorded before placing in an electric oven at $105^{\circ} \mathrm{C}$ for $24 \mathrm{~h}$, then the weight of the shell was recorded again and the percentage of moisture content was calculated (Sobral et al., 2001).

\section{Rupture test}

Three air filled soft gels with fill formulation were subjected to rupture test for softgels using USP apparatus II operated at 50 rpm in $500 \mathrm{ml}$ water for 15 minutes where each capsule was fitted in a sinker to avoid floating of capsule to the surface of the medium (USP, 2013).

\section{Mechanical properties}

The mechanical properties of capsules film were determined through a locally made tensile strength tester. Rectangular strip (2.5 $\mathrm{cm} \times 2 \mathrm{~cm}$ ) was hanged in the tensile strength tester between the two jaws of the device and keeping $1 \mathrm{~cm}$ length of the strip between them. The strip was then stretched by rolling the plastic wheel of the device. The weight in kilograms (breaking load) and the length of the elongated strips at which the strip cuts, were recorded. The average of six tested strip was calculated for each formula in softgels. Puncture force (PF), tensile strength (TS), Young modulus of elasticity (ME) and percentage of elongation (\%PE) were calculated (Elgindy et al., 2009)

\section{Stability studies}

Stability study was carried out on air filled soft gelatin capsules injected with selected fill formulations for 3 months in a stability cabinet (Vötsch, Germany) at controlled relative humidity $\left(\mathrm{RH} 55 \& 40^{\circ} \mathrm{C}\right)$ and on shelf at $\left(25^{\circ}, 65 \% \mathrm{RH}\right)$. Formulations were assessed for in vitro dissolution profile 
and rupture test for softgel before and after storage.

\section{RESULTS AND DISCUSSION}

ETO is one of the selective COX-2 inhibitors; it possesses 10-fold COX-2 selectivity over COX-1 responsible to produce prostaglandins concerned in cytoprotection of gastric mucosa and controlling the renal blood flow. It safely treats inflammatory disorders without causing gastric irritation، ulceration, or bleeding (Tsuneoka et al., 2005). It is practically water insoluble drug and is considered to be a class II drug(Okamoto et al., 2008). LBFs utilizing softgel technology have been used as a potential strategy for enhancing the oral bioavailability of ETO as a highly lipophilic, poorly water-soluble drug candidate.

\section{Preparation of LBFs of ETO}

Griffin (Griffin, 1949) stated that the required HLB values for blends of oils could be determined in a manner similar to that for blends of emulsifiers. For oily mixture, it was shown that at HLB value $=6$, the prepared emulsion was physically stable showed no creaming or segregation between the oily and aqueous phase. Upon dispersion of ETO with LBFs, no creaming or segregation between the oily and aqueous phase was observed with LBFs containing oil only or with lipophilic surfactant demonstrating good physical stability while separation has occurred with LBFs containing hydrophilic surfactants, which could be ascribed to a difference between HLB value of these hydrophilic surfactants and the required HLB value of the dispersion medium.

It was shown experimentally that the appropriate ratio between ETO powder and oily mixture to prepare a flowable suspension able to be proceed via softgel encapsulation machine was 1:2. Solubility studies showed a limited solubility of ETO in soya bean oil

\section{ISSN (on-line) 2356_9786}

(12.7 mg/gm). Accordingly, ETO was well dispersed in Type I, II LBFs (F1, F2, and F3) with no sedimentation or aggregation due to compatibility of lipophilic surfactants with the low required HLB value of the oily mixture $(\mathrm{HLB}=6)$.

On dispersion of ETO in F4 and F8 (Type IIIa LBFs) containing 20\% CRM RH 40 (HLB value $=14-16)$ and $20 \%$ of hydrophilic surfactant blend $(17.78 \%$ CRM EL and 2.22\% PLX 407, HLB value = 13.8) respectively, relative small aggregates were observed. This may be attributed to difference between HLB value of used hydrophilic surfactants in such formulations and the required HLB of the oily mixture(Schramm, 2005). On other hand, on dispersion of ETO in F5 containing 20\% PLX 407 (HLB value = 18-23), large aggregates of ETO were observed and completely separated from the oily mixture, this may be attributed to high difference in HLB value between PLX 407 and required HLB of oily mixture. This difference is more than that in case of F4 and F8. However, an advantage of using a mixture of PLX 407 and CRM EL was to obtain the best results for in-vitro dissolution profile of ETO using small concentration of PLX 407 with better physical properties if compared to F5 via reducing the formation of large rigid flakes.

Different concentrations of cosolvents (PG and PEG 400) were examined to solubilize the hydrophilic surfactant PLX 407 in F6 and F7, respectively. It was revealed that at concentration less than $40 \%$, aggregates were still formed and the optimum concentration of co-solvents to solubilize PLX 407 was 60\%. Accordingly, upon dispersion of ETO in the selected hydrophilic co-solvent mixtures, no aggregates were formed.

For Type IV LBFs (F9), CRM RH 40 was warmed at $40^{\circ} \mathrm{C}$ to a liquefied form and 
ETO was dispersed in the formed dispersion medium. No aggregates or separation were seen during preparation and mixture was homogenously dispersed.

\section{Drug content}

Percent drug content ranged from $101.4 \pm 0.030$ to $113.43 \pm 0.048$ indicating that ETO was well dispersed in all formulas leading to acceptable blend consistency during filling process and content uniformity in the final softgel product.

\section{In-vitro dissolution study}

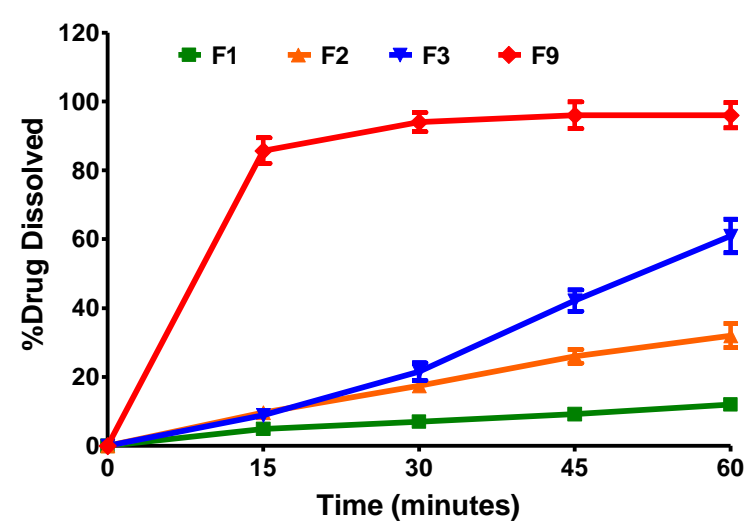

\section{ISSN (on-line) 2356_9786}

According to USP requirements for dissolution test; not less than $75 \%$ of the labeled amount of ETO capsule is dissolved in 30 mins (USP, 2013). A comparative dissolution profiles among different LBFs were performed to show the effect of LFCs on the dissolution behavior of ETO in phosphate buffer $\mathrm{pH} 6.8$ and graphically illustrated in Figure 1. The parameter used to estimate dissolution behavior was the percent dissolved after $30 \mathrm{~min}$ (PD30).

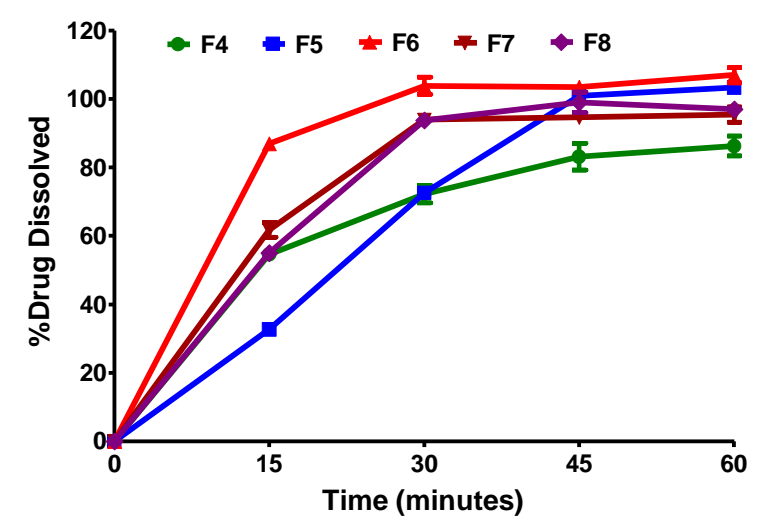

Fig. 1: Dissolution profile of ETO from different LBFs in phosphate buffer $\mathrm{pH} 6.8 \pm 0.1$ at $37^{\circ} \mathrm{C} \pm 0.5^{\circ} \mathrm{C}$

PD30 for Type I (F1) and Type II (F2, F3) formulations were below the USP requirements for ETO dissolution (7\%, $17.53 \%$, and $21.56 \%$ respectively); F2 was only selected for characterization of Type II in further studies. PD30 for Type IIIa (F4, F5, F8) and Type IIIb (F6, F7) formulations were $76.27 \%, 75.43 \%, 93.77 \%, 103.4 \%, 94 \%$ respectively. All the investigated softgel formulae achieved the USP requirement for ETO capsule dissolution. Similarly, formulation of ETO in Type IV (F9) showed good dissolution results $(\mathrm{PD} 30=93.4 \%)$. Although relative good dissolution results of F5, it was excluded from the chosen formulations in the study due to difficulty to inject softgels with F5 due to its large rigid flakes.
It was proposed that Type I systems have inadequate capacity to be self-dispersed in water and rely on digestion to assist colloidal dispersion through solubilization of digestion products in mixed micelles (Pouton et al., 2007). Similarly, in Type II systems, water insoluble surfactants showed poor hydrophilicity to dissolve and form micelles in solution and endorse the emulsification of lipid in the aqueous phase (Pouton 2000; Pouton and Porter 2007). All the investigated Type III formulations (F4-F8) achieved the USP requirement for ETO capsule dissolution. It was declared that the water-soluble components will be likely to deprive the oil throughout dispersion and dissolved in the aqueous phase resulting in phase separation, which may actually be the dynamic force for emulsification (Pouton, 2000). Combination 
between two hydrophilic surfactants (F8) showed better results than using single hydrophilic surfactant. Type IIIb formulations showed better results than Type IIIa. Pouton (Pouton and Porter 2007) stated that inclusion of co-solvents (PEG 400 or PG) in LBFs will bring about enhancement in the solvent capacity of the formulation for drugs which dissolve freely in co-solvents and assist in dispersion of systems enclosing high percentage of hydrophilic surfactants, also inclusions of co-solvents are useful in reduction variability and irritancy caused by high local concentrations of surfactants (Pouton 2006 ). Type IV formulation showed good dissolution results, The standard correlation among drug solubility for a micellar system and concentration of solubilizing agent was previously reported (Pouton and Porter 2007). It was conveyed that drug will precipitate from the co-solvent solution but stay in solution upon diluting micellar system which is consistent with our results. Formulation of ETO in a pure water soluble surfactant (F9) showed better dissolution results than pure co-solvent system.

\section{Water migration studies}

Results of water migration study of ETO fill formulations were presented in Table 2. The shell material of dry softgels regularly enclosed $10-15 \%$ w/w water dependent on the type of gelatin shell used (Hom et al.,

\section{ISSN (on-line) 2356_9786}

1975), where it was acknowledged that water content in gelatin was assumed to correspond to the water sorbed its polar groups (Yakimets et al., 2005). Results revealed that water migration among the fill, the shell and the surrounding atmospheric humidity depend on the fill composition of ETO formulation.

Fill formulations in F1, F2 and F9 were not affected on the water migration process between the shell and the surrounding medium where the shell was equilibrated with the surrounding medium by decreasing the percentage of the water content to reach 7-9\%. Water had migrated from the shell to fill content in F4 and F8 leading to an increase in the water content to reach $1.8-2.5 \%$ and from the shell to the surrounding medium to reach 7.8-8.8\%. This might be ascribed to presence of a relative low concentration of CRM RH 40 and CRM EL in high concentration of oil (i.e. $80 \%$ ) which tends to increase the water uptake of the fill components. PG in F6 was more than $10 \%$ of the total fill formulation leading to migration of a portion of propylene glycol to the shell acting as a plasticizer and water content raised inside to $4.1 \%$; conversely, moisture was absorbed by the shell from the surrounding medium with increasing in moisture content in the shell to reach $18.3 \%$. Water was migrated from shell components into F7 fill to raise water content to $3.8 \%$ owing to presence PEG 400 with high water affinity.

Table 2: Dynamics of Water Migration from different prepared Soft-gel

\begin{tabular}{ccccc}
\hline \multirow{2}{*}{ Formula } & \multicolumn{4}{c}{ Percent Moisture Content } \\
\cline { 2 - 5 } & \multicolumn{2}{c}{ Before Equilibrium } & \multicolumn{2}{c}{ After Equilibrium } \\
\cline { 2 - 5 } Fill & Shell & Fill & Shell \\
\hline F1 & $0.10 \pm 0.003$ & $14.5 \pm 0.009$ & $0.70 \pm 0.003$ & $9.0 \pm 0.023$ \\
F2 & $0.20 \pm 0.003$ & $14.5 \pm 0.009$ & $0.50 \pm 0.002$ & $7.6 \pm 0.002$ \\
F4 & $0.60 \pm 0.002$ & $14.5 \pm 0.009$ & $2.50 \pm 0.001$ & $8.8 \pm 0.009$ \\
F6 & $0.80 \pm 0.003$ & $14.5 \pm 0.009$ & $4.10 \pm 0.009$ & $18.3 \pm 0.019$ \\
F7 & $0.40 \pm 0.005$ & $14.5 \pm 0.009$ & $3.80 \pm 0.005$ & $5.8 \pm 0.027$ \\
F8 & $0.32 \pm 0.005$ & $14.5 \pm 0.009$ & $1.83 \pm 0.013$ & $7.8 \pm 0.002$ \\
F9 & $2.20 \pm 0.001$ & $14.5 \pm 0.009$ & $2.70 \pm 0.001$ & $7.0 \pm 0.003$ \\
\hline
\end{tabular}


Presence of a relative low concentration of CRM RH 40 and CRM EL in high concentration of oil (as in F4 and F8) increased the water uptake of the fill components. The effect of co-solvents either PG or PEG 400 on water migration was also studied, a portion of PG in F6 was anticipated to migrate to the shell to act as a plasticizer and water migration from the shell to the fill may be explained by hygroscopicity of PG leading to raising water content inside, moisture was also absorbed by the shell from the surrounding medium. In contrast, PEG 400 was not reported to migrate to shell composition; shell does not absorb moisture from the surrounding medium reaching equilibrium with fill content.

\section{Mechanical properties}

Typical mechanical properties were presented in Table 3. Empty softgels were applied in this test to figure out the effect of the fill content of ETO formulations on the mechanical strength of shell of softgel. A slight decrease was observed in F1 on comparing with empty softgels. In case of F2, F4, F8 and F9, presence of more than $10 \%$ surfactants lead to an increase in the mechanical properties of the shell. Meanwhile, a sharp decrease in the mechanical properties of the shell of F6 was demonstrated. Migration of PG from the fill to the shell of F6 increased the elasticity of the softgel shell and possibility for deformation (Gullapalli 2010) due to its plasticizing properties which was in agreement with results of water migration studies.

In case of F7, an increase in the mechanical properties was also perceived leading to reduction of elasticity where the fill content composed of low molecular weight PEG owing to high affinity of low molecular weight PEG for water and glycerin used in the shell formulations (Pasquali et al., 2008). Movement of plasticizer from the shell into the fill might give rise to reduction in elasticity and increase in brittleness of the shell abruptly after production or during storage (Gullapalli 2010).

Table 3: Puncture force (PF), tensile strength (TS), Young modulus of elasticity (ME) and elongation at break (EB) of softgels

\begin{tabular}{ccccc}
\hline \multirow{2}{*}{ Formula } & \multicolumn{4}{c}{ Mechanical properties } \\
\cline { 2 - 5 } & PF (N) & TS (Mpa) & ME (Mpa) & EB (\%) \\
\hline Empty softgels & $9.53 \pm 2.400$ & $0.430 \pm 0.200$ & $0.140 \pm 0.070$ & $306.0 \pm 0.21$ \\
F1 & $8.60 \pm 3.970$ & $0.270 \pm 0.185$ & $0.140 \pm 0.078$ & $171.5 \pm 0.20$ \\
F2 & $15.89 \pm 2.128$ & $0.748 \pm 0.125$ & $0.220 \pm 0.038$ & $344.0 \pm 0.60$ \\
F4 & $17.15 \pm 4.410$ & $0.786 \pm 0.091$ & $0.292 \pm 0.120$ & $295.0 \pm 0.93$ \\
F6 & $3.40 \pm 0.577$ & $0.165 \pm 0.041$ & $0.060 \pm 0.010$ & $272.0 \pm 0.40$ \\
F7 & $16.28 \pm 1.120$ & $0.850 \pm 0.166$ & $0.300 \pm 0.054$ & $286.0 \pm 0.60$ \\
F8 & $11.37 \pm 2.030$ & $0.637 \pm 0.130$ & $0.216 \pm 0.058$ & $302.6 \pm 0.53$ \\
F9 & $16.66 \pm 2.070$ & $0.915 \pm 0.220$ & $0.320 \pm 0.157$ & $311.0 \pm 0.77$ \\
\hline
\end{tabular}

\section{Stability studies}

\section{In-vitro dissolution}

F7, F8 and F9 were subjected to accelerated and shelf stability studies for 3 months in comparable with their dissolution results at zero time and graphically showed in Figure 2. A sharp decrease in dissolution profile of $\mathrm{F} 8 \quad(31 \%$ after $30 \mathrm{~min})$ was observed. Presence of CRM EL in fill content of F8 and F9 which is encountered to be a material containing polyoxyethylene (POE) moiety in its structure that is susceptible to autoxidation in the presence of oxygen generating reactive peroxide (Kumar et al., 2006; Li et al., 2007; Wasylaschuk et al., 2007) was the key point in decreasing 
dissolution profile after accelerated stability study. It has been also hypothesized that POE moieties could be decomposed by oxidation to ethylene glycol then formaldehyde at high temperature in the presence of water (Frontini et al., 1995). On the contrary, after shelf stability, a slight decrease in the dissolution result of ETO after 30 min to reach $76.43 \%$ demonstrating incomplete autoxidation reaction of CRM EL. No change in dissolution results of F7 was observed after accelerated and shelf stabilities which could be attributed

\section{ISSN (on-line) 2356_9786}

to high molecular weight of PLX 407 present in the fill content of the formula leading to decrease in the mobility of polymer chains and subsequently decrease in the autoxidation reactions(Li et al., 2007).

Although F9 revealed that dissolution of ETO decreases to $81 \%$ after $30 \mathrm{~min}$ but it still lined with pharmacopeial requirements. Partial autoxidation CRM RH 40, could be the reason for such decrease but to lesser extent if compared to F8 formula (Barrio et al., 2006; Li et al., 2007).
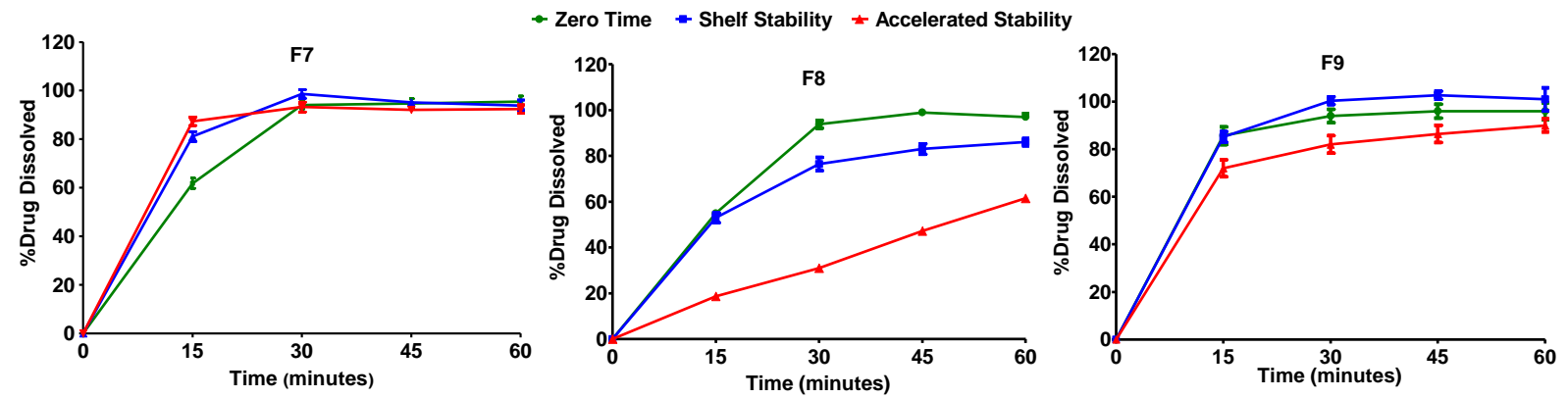

Fig. 2: Dissolution profile of ETO from selected formulations after shelf and accelerated studies for 3 months

\section{Rupture test}

Absorption of a compound formulated in a softgel depends on shell rupture after initial dissolution and consequent release of its fill contents in the GIT fluids. Thus, both processes need to be observed throughout the release and storage of a softgel product. It was reported that failure in shell rupture may come out upon aging when exposed to physical or chemical situations that bring about gelatin shell to turn into swollen and water insoluble mass (Gullapalli 2010). ETO softgels were subjected to rupture test to examine the effect of fill content on the dissolution of softgel shell at zero time and after stability studies. The fill content of all tested formulations has no effect on dissolution of the gelatin shell at zero time and after shelf stability as shown in

\section{Table 4.}

Table 4: Rupture test of ETO softgels at zero time and after stability studies for 3 months

\begin{tabular}{llll}
\hline Formula & Zero & Shelf & Accelerated \\
\hline
\end{tabular}

\begin{tabular}{ccccc}
\hline & Time & Stability & \multicolumn{2}{c}{ Stability } \\
\cline { 2 - 5 } & $\begin{array}{c}\text { After } \\
\text { 15 mins }\end{array}$ & $\begin{array}{c}\text { After 15 } \\
\text { mins }\end{array}$ & $\begin{array}{c}\text { After } \\
\text { 15 mins }\end{array}$ & $\begin{array}{c}\text { After } \\
\text { 30 mins }\end{array}$ \\
\hline F 1 & + & + & + & - \\
F 2 & + & + & + & - \\
F 4 & + & + & - & - \\
F 7 & + & + & - & + \\
F 8 & + & + & - & - \\
F 9 & + & + & - & - \\
\hline
\end{tabular}

Note: (+) ruptured, (-) Failed to ruptured

After accelerated studies, the fill content of F1, F2 and F7 cause no deterioration of the softgel shell. In case of F4, F8 and F9; fill contents affected on dissolution and rupture of gelatin shell resulting in pellicle formation. Presence of either CRM EL or CRM RH 40 as materials with POE moiety in fill contents was liable to autoxidation producing reactive organic peroxides which further corrupted to create short chain carboxylic acids and aldehydes of gelatin shell (Ofner et al., 2001). It is well recommended that antioxidants should be added to 
Zagazig J. Pharm. Sci. Jun, 2017

Vol. 26, Issue 1, pp, 1-12

formulations containing hydrophilic surfactants which composed of POE moiety.

\section{CONCLUSION}

The current work adopted development of ETO softgel formulation based on LBCs in addition to studying the effect of these formulations on the stability of softgels. A good relationship regarding the composition of the softgel core fill and drug dissolution parameters was set up and type $\mathrm{III}_{\mathrm{b}}$ and IV LBFs were selected to be the most suitable types for drug dispersion. Application of hydrophilic surfactants showed a remarkable enhancement in the dissolution rate of etodolac. Antioxidants should be added to formulations containing hydrophilic surfactants that composed of POE moiety to protect it from autoxidation process. Formulations containing hydrophilic SAA/cosolvent blend were selected to be the most appropriate LBFs for a highly lipophilic drug candidate in softgels. A more complete understanding already at an early stage of drug development allows the formation of new, much more efficient lipid-based drug delivery systems that minimize drug precipitation.

\section{CONFLICT OF INTEREST}

The authors declare no conflicts of interest.

\section{REFERENCES}

Aboul-Einien M. H. (2009): Formulation and evaluation of felodipine in softgels with a solubilized core,. Asian J Pharm Sci, 4: 144-160.

Barrio M. D., Hu J., Zhou P. and Cauchon N. (2006): Simultaneous determination of formic acid and formaldehyde in pharmaceutical excipients using headspace GS/MS. J Pharm Biomed Anal 41: 738-743.

Benza H. I. and Munyendo W. L. (2011): A review of progress and chanllenges in soft gelatin capsules formulations for
1SSN 2356_9786

ISSN (on-line) 2356_9786

oral adminstration. Int J Pharm Sci Rev Res 10: 20-24.

Bottom C. B., Clark M. and Carstensen J. T. (1997): Dissolution testing of soft shell capsules-Acetaminophen and nifedipine. J Pharm Sci 86: 1057-1061.

Elgindy N. and Samy W. (2009): Evaluation of the mechanical properties and drug release of cross-linked Eudragit films containing metronidazole. Int J Pharm, 376: 1-6.

Frontini R. and Mielck J. B. (1995): Formation of formaldehyde ina polyethylene glycol and in poloxamer under stress conditions. Int J Pharm 114: 121-123.

Griffin W. C. (1949): classification of surface active agents by "HLB". J Soc Cosm Chem 315-318.

Gullapalli R. P. (2010): Soft gelatin capsules. J Pharm Sci 99: 4107- 4148.

Hauss D. J. (2007): Oral Lipid Based Formulations: Enhancing the bioavailability of poorly water soluble drugs, Informa healthcare. USA, Inc.

Hom F. S., Veresh S. A. and Ebert W. R. (1975): Soft gelatin capsules II. Oxygen permeability study of capsule shells. J Pharm Sci, 64: 851-857.

Hong S. S., Lee S. H. and Lee Y. J. (1998): Accelerated oral absorption of gliclazide in human subjects from a soft gelatin capsule containing a PEG400 suspension of glicazide. J Control Rel, 51: 185-192.

Ibrahim M. M., El-Nabarawi M. and ElSetouhy D. A. (2010): Polymeric surfactant based etodolac chewable tablets: formulation and in vivo evaluation. AAPS PharmSciTech, 11: 1730-1737.

Jones W. J. (2000): Softgels: consumer perceptions and market impact relative 
to other oral dosage forms. Advances In Therapy, 17: 213-221.

Karataş A., Yuksel N. and Baykara T. (2005): Improved solubility and dissolution rate of piroxicam using gelucire 44/14 and labrasol. Il Farmaco, 60: 777-782.

Kumar V. and Kalonia D. S. (2006): Removal of peroxides in polyethylene glycols by vacuum drying: Implications in the stability of biotech and pharmaceutical formulations. AAPS PharmSciTech, 7: E1-E7.

Li Z., Kozlowski B. M. and Chang E. P. (2007): Analysis of aldehydes in excipients used in liquid/semi-solid formulations by gas chromatographyNegative chemical ionization mass spectrometry. J Chromatography A, 1160: 299-305.

Schramm L. L. (2005): Emulsions, foams and suspensions: fundamentals and applications, John Wiley and Sons Ltd. PP. 299-305

Ofner C. M., Zhang Y., Jobeck V. C. and Bowman B. J. (2001): Crosslinking studies in gelatin capsules treated with formaldehyde and in capsules exposed to elevated temperature and humidity. J Pharm Sci, 90: 79-88.

Okamoto A., Shirakawa T., Bito T., Shigemura K., Hamada K. and Gotoh A. (2008): Etodolac, a selective cyclooxygenase-2 inhibitor, induces up-regulation of E-cadherin and has antitumor effect on human bladder cancer cells in vitro and in vivo. . Urology, 71: 156-160.

Pasquali R. C., Taurozzi M. P. and Bregni C. (2008): some considerations about the hydrophilic-lipophilic balance system. Int J Pharm, 356: 44-51.

Patel M., Patel S. and Patel N. (2011): A review: Novel oral lipid based formulation for poorly soluble drugs. Int J Pharm Nanotech, 3: 1183-1189.

Porter C. J., Pouton C. W., Cuine J. F. and Charman W. N. (2008): Enhancing intestinal drug solubilization using lipid-based delivery systems. Adv Drug Deliv Rev, 60: 673-691.

Pouton C. W. (2000): Lipid formulations for oral administration of drugs: Nonemulsifying, self-emulsifying and 'self-microemulsifying' drug delivery systems. Eur J Pharm Sci, 11: S93S98.

Pouton C. W. (2006 ): Formulation of poorly water-soluble drugs for oral administration: Physicochemical and physiological issues and the lipid formulation classification system. Eur J Pharm Sci, 29: 278-287.

Pouton C. W. and Porter C. J. (2007): Formulation of lipid-based delivery systems for oral administration: Materials, methods and strategies. Adv Drug Deliv Rev, 60: 625-637.

Sobral P. J., Menegalli F. C., Hubinguer M. D. and Roques M. A. (2001): Mechanical, water vapor barrier and thermal properties of gelatin based edible films. Food Hydrocoll 15: 423-432.

Soumya S., Dony A. and Sabitha A. (2012): Current trends in lipid based delivery systems and its applications in drug delivery. Asian J Pharm Clin Res, 5: 49.

Tsuneoka N., Tajima Y., Kitazato A., Fukuda K., Kitajima T. and Kuroki T. (2005): Chemopreventative effect of a cyclooxygenase-2- specific inhibitor (etodolac) on chemically induced biliary carcinogenesis in hamsters. Carcinogenesis, 26: 465-469.

USP (2013).Thirty six edition. National Formulary, 31th edition. 
Wasylaschuk W. R., Harmon P. A., Wagner G., Harman A. B., Templeton A. C., $\mathrm{Xu}$ H. and Reed R. A. (2007): Evaluation of hydroperoxides in common pharmaceutical excipients. J Pharm Sci 96: 106-112.

Yakimets I., Wellner N., Smith A. C., Wilson R. H., Farhat I. and Mitchell J. (2005): Properties with respect to water content of gelatin films in glassy state. Polymer, 46: 12577-12585.

Yang S. G., Kim D. D. and Chung S. J. (2006): Stable bioavailability of
ISSN (on-line) 2356_9786

cyclosporin A, regardless of food intake from soft gelatin capsule containing a new self emulsifing formulation. Int $\mathrm{J}$ Clin Pharmacol Ther, 44: 233-239.

Yazdanian M., Briggs K., Jankovsky C. and Hawi A. (2004): The "high solubility" definition of the current FDA Guidance on Biopharmaceutical Classification System may be too strict for acidic drugs. Pharm Res, 21: 293299.

\section{كبسولات جيلاتينية رخوة من الايتودولاك: تقييم ودراسة جدوي استعمال التحضيرات دهنية الوسط لدواء غير محب للماء ودراء}

$$
\text { أحمد نبيل علام - إبر اهيم عبد المحسن كميل - أسامة يوسف عبد الله }
$$

توفر التركيبات دهنية الوسط عن طريق الفم فرصة كبيرة للادوية شحيحة الذوبان ومتغيرة الامتصاص عن طريق الجهاز الهضمي. من المفيد مناقتة كيف يمكن صياغة استر اتيجيات مختلفة للتغلب على بعض التحديات التي يطرحها استعمال الكبسو لات الجيلاتينية الرخوة لتطوير الادوية الغير محبة للماء ذات الجرعات العالية. تم صياغة عقار الايتودولاك في المركبات الدهنية المختلفة وفقا لنظام تصنيف الدهون لتحسين تركيبة التعبئة المناسبة وتم اجر اء اختبار ات مختلفة للتوصيف. و أجريت أيضا در اسات هجرة المياه واختبار تمزق الكبسو لات والخواص الميكانيكية للكبسولات الجيلاتينية الرخوة للتحقيق من تأثير مو اد الصياغة على سلامة وثباتية الكبسو لات بالاضافة الي انطلاق الدواء من الصباغات المحضرة. تم تقييم انطلاق العقار واختبار تمزق الكبسولات من تركيبات مختارة تحت شروط تخرين متسارعة وعلي الرف بعد ثلاث اشهر. وكثفت النتائج وجود علاقة بين تكوين السائل الداخلي للكبسولات ومعدل انطلاق الدواء كما اظهر استعمال المواد النشطة سطحيا المحبة للماء تحسن في معدل انطلاق الدواء من وند التركيباتو ان معدل هجرة المياة بين محتوي وغلاف الكبسولات يعتمد علي تركيب الغلاف ودرجة قبوله للماء. يجب إضافة مضادات الأكسدة إلى تركيبات تحتوي المواد النشطة سطحيا المحبة للماء والتي تتكون من بوليوكسي إيثيلين. أظهرت الصيغة المرشحة التي تحتوي على بولي إثيلين غليكول / بولوكسامار V.ــ نتائج انطلاق دواء جيدة ومستقرة بعد اختبار الثباتية بالإضافة إلى نتائج ميكانيكية أفضل. 